\title{
The elderly and the digital inclusion:A brief reference to the initiatives of the European union and Portugal
}

\begin{abstract}
Background: The world and Europe, in particular, are aging very fast, and in the same vein, digitization is moving very quickly into citizens' routines. Given the fact that the elderly are the largest group of citizens who are info-excluded, this reality is worrying because it will quickly make them socially excluded. This article briefly presents the main initiatives of the European Union and Portugal to promote greater and faster digital inclusion of the elderly people. In the final section, there is a critical reflection on technology acceptance Model, the concept of universal design and usability in order to propose clues and strategies that can and/or may facilitate the use and access of technologies and digital resources by the elderly.
\end{abstract}

Keywords: elderly, digital divide, technology acceptance model, universal design, usability
Volume 4 Issue 6 - 2019

Henrique Gil
Age.Comm, Polytechnic Institute of Castelo Branco, Portugal

Correspondence: Henrique Gil,Age.Comm, Polythecnic Institute of Castelo Branco, Av. Pedro Álvares Cabral, n. ${ }^{\circ} 12$, 6000-084 Castelo Branco, Portugal, Tel +35I 272339600, Email hteixeiagil@ipcb.pt

Received: October 24, 2019 | Published: November 01, 2019
Abbreviations: AAL, ambient assisted living; ENILD, national strategy for inclusion and digital literacy; HCI, human-computer interaction; TRA, theory of reasoned action; TAM, technology acceptance model; MM, motivational model; TPB, theory of planned behavior; CTPB-TAM, combined theory of planned behavior/ technology acceptance model; MPCU, model of pc utilization; IDT, innovation diffusion theory; SCT, social cognitive theory; UTAUT, unified theory of acceptance and use of technology

\section{The ageing process: the reality and prospects in the European Union and Portugal}

The economic growth that has taken place has made it possible for citizens to access more and better health care, to have the possibility of eating healthy, to enjoy better conditions for sports, which has enabled the growth of life expectancy especially in the most developed countries. In the opposite direction, there was a decrease in the number of births which translated into a low fertility rate. These two phenomena evolved in reverse and as a result we have witnessed a progressive aging within the most developed countries. According to EU projections ${ }^{1}$ EU-28 countries will rise from 512 million in 2018 to around 525 million in 2044 with a slight decrease in 2050 . For older people (65+years) its increase will rise from 101 million in 2018 to about 149 million in the year 2050. However, older citizens aged 7584 will grow by an estimated $60.5 \%$ while citizens aged $65-74$ will increase by $17.6 \%$. On the opposite, by the year 2050 there will be only $9.6 \%$ of EU-28 citizens under 55 years. These projections show the relative importance of the very old $(85+$ years) that is growing at a faster pace than any other age group dur to its increase from 13.8 million in 2018 to 31,8 million by $2050 .{ }^{1}$ Figure 1 presents an overview of the people aged $55+$ years, by age class during the period 2018-2050:

The Figure 1 presents the projections by country that allows observing that by 2050 citizens aged 55+years will represent almost half of the population of Portugal (47.1\%) as the most serious example of the process of ageing across the EU-28 countries. In this sense, and as a result of this progressive aging process, the projections of the EU-28 point to a population aged 0-14 at 15\% by 2070. Conversely, the population aged $65+$ years will reach $29 \%$ of the total population and the population aged $80+$ years will represent around $13 \%{ }^{2}$

In order to clarify all the previous statements the Figure 2 presents the age and gender pyramid for the period 2016-2070 to clarify the progressive aging process in the EU-28 with the already referenced accelerated increase for older citizens.

Overall this reality has brought about another consequence at the level of the so-called old-age dependency ratio i.e. aged people $65+$ years relative to those aged 15-64. For the EU-28 an increase of $21.6 \mathrm{pps}$ is projected. This value is the result of the $29.6 \%$ increase in 2016 to $51.2 \%$ in the year 2070 . In practice it will mean that there will be on average 2 seniors for only 1 active citizen we will also have to be mindful of the significant increase in the population with $85+$ years. According to those projections Portugal will have the old-dependency ratio exceed 35 pps over the projection horizon. ${ }^{2}$ 


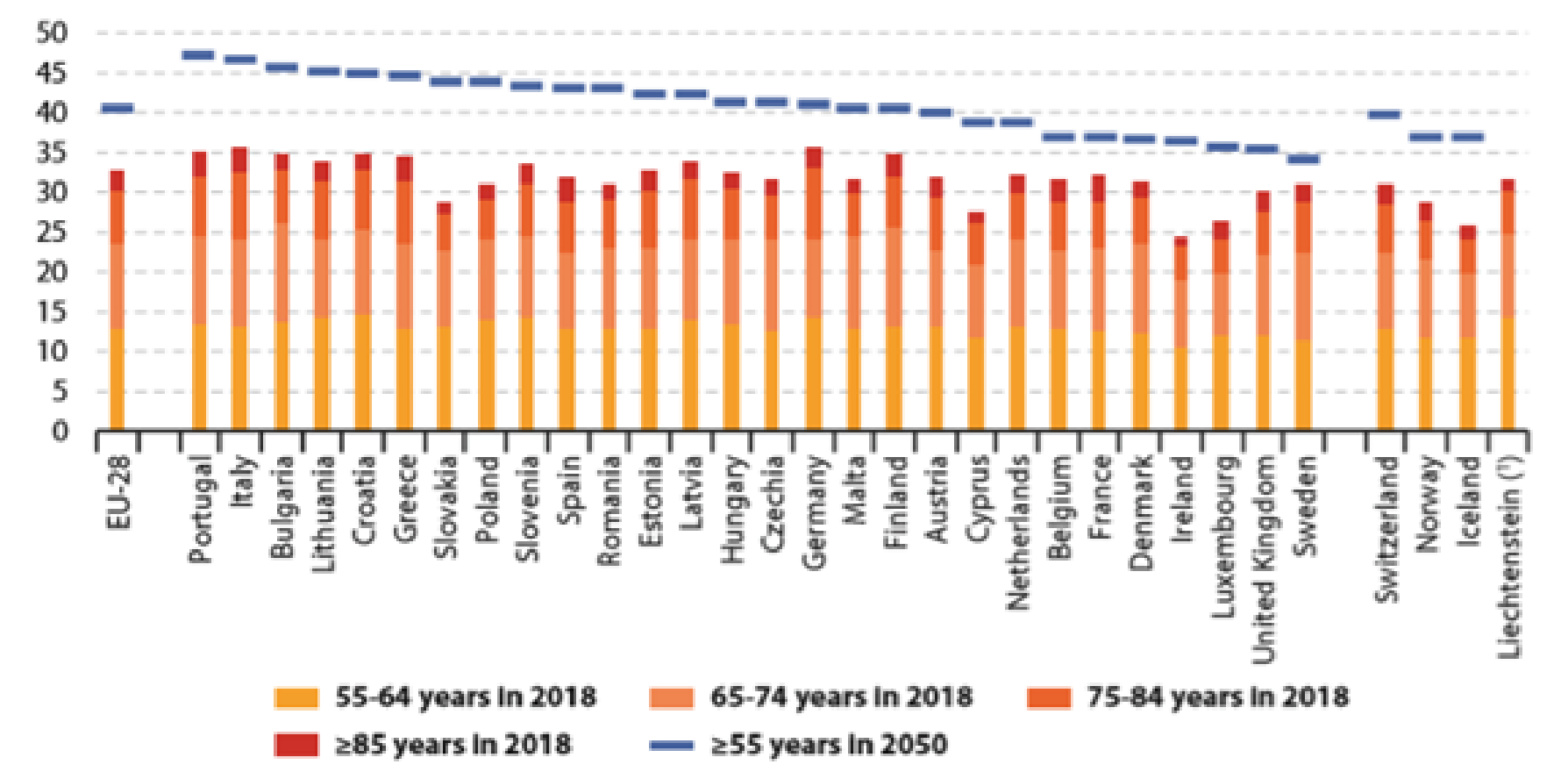

Figure I People aged 55+years by age class during the period 2018-2050.'

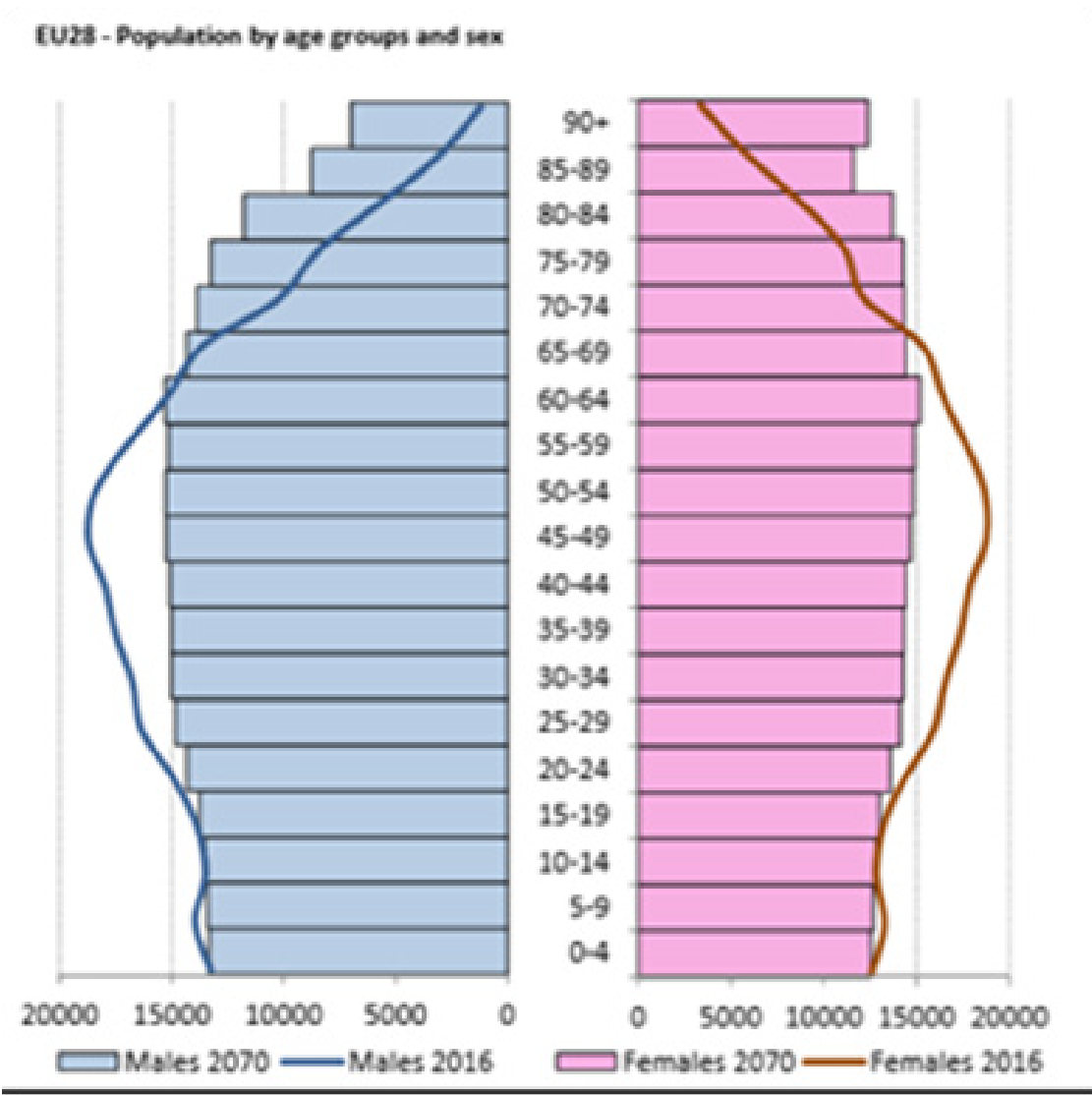

Figure 2 Population by age group and gender for the period of 2016-2070. ${ }^{2}$ 
The elderly and digital skills: main initiatives for the info inclusion (European Union and Portugal)

Being aware of the existence of a generational gap that has become larger over the years, when we analyze the population distribution in relation to digital skills, we realize that there is also a digital gap.
Figure 3 presents the data on internet use by younger people which is higher compared to the rest of the population. This daily use is the result of increased broadband coverage allowing easier access at home. In the same vein there has also been a significant increase in wifi spaces both in public services and in commercial spaces. For young people the use of the internet is a resource for educational activities, to access and communicate with their friends through social networks and to play online.

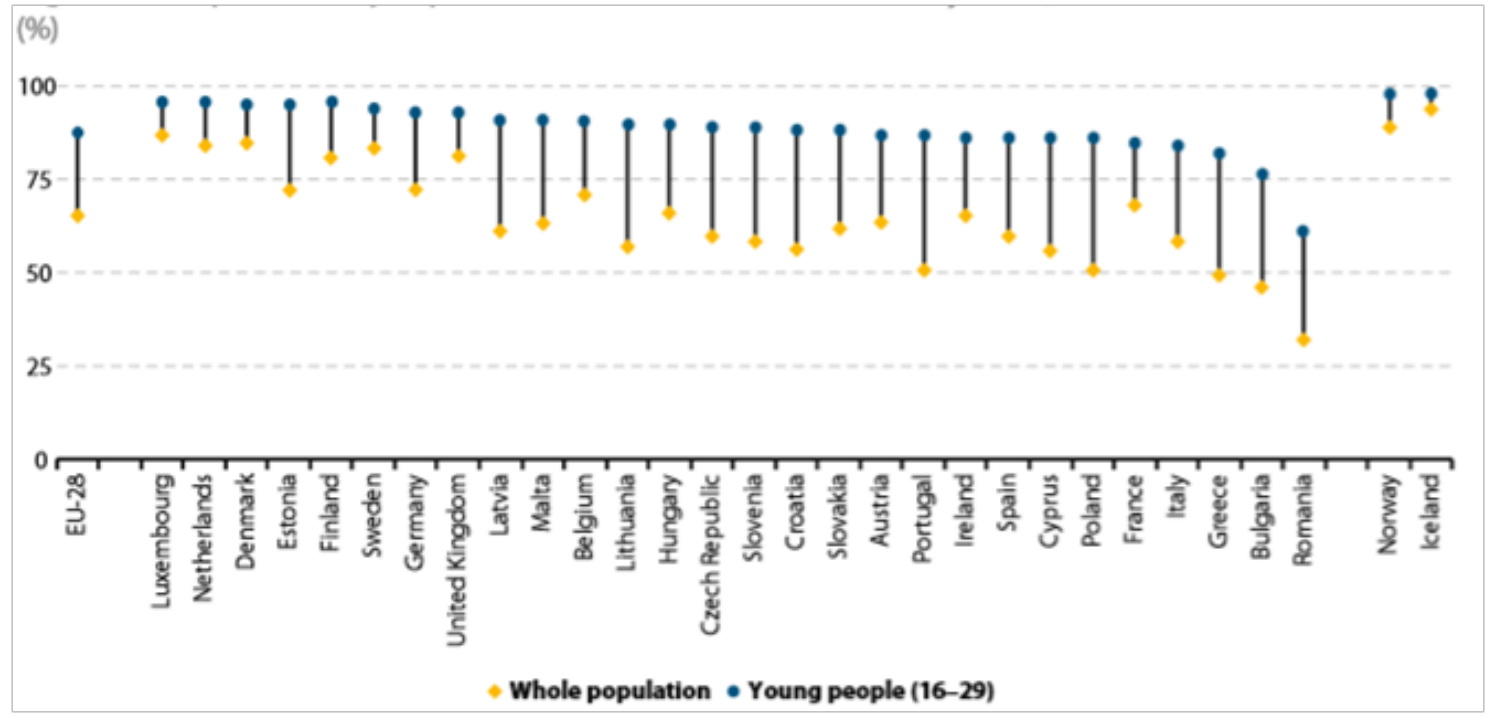

Figure 3 Proportion of people who used the internet on a daily basis, 2014 (Source: Eurostat, 2015).

Observing the Figure 3 , it is also possible to see that the difference in use between young people and the general population is $25 \%$ (average) in the EU-28. On the contrary, there are countries like Portugal where this difference is about $30 \%$. In the northern European countries this is where there is a smaller difference that can be close to only $5 \%$.

These data already show the greater tendency, in general, for younger people to integrate digital technologies in most of their daily routines. Based on the concept of digital natives enunciated by Marc Prensky, the youngest were born in a context where digital technologies and resources already existed. For this reason there are also those who claim that technologies and these digital resources come into your life as true extensions of your body.

In another sense, older citizens also called digital immigrants were born and developed all their educational, labor, economic and social activities in an environment where technologies did not exist or were scarce. Even without these technologies and digital resources, older citizens developed their work activity and were socially integrated citizens. That is, all of their daily routines were executed without having to know how to use and access technologies and most were successful. As digital technologies and resources were being introduced, digital immigrants had to accommodate themselves to this new reality.

The first adaptation was mostly in the workplace through the use of digital platforms adapted to production or services. These adaptations was being carried out with some effort but were able to respond to the request by the employer. Although digital inclusion was being promoted through the workplace that required personal routines, it was still being carried out without the obligation or need to access and use digital technologies and resources.
In another dimension, digital natives, even if they do not want digital technologies and resources, are ubiquitous and their exposure to them makes their routines almost compulsorily access and use them. In the same vein, we have been witnessing an increasing dematerialization of processes and services as a transformation and the transition from an analogical context to a digital context.

Another variable that should be considered also has to do with the fact that equipment and its upgrades become quite intuitive for younger people. In a very easy way, we can see new performances and new performances with equipment and digital resources. There is a feeling that these digital solutions are tailored to the interests and motivations of young people. If this value judgment is correct, it is easy to prove and to understand. The designers of these new digital features and equipment are young and in designing new solutions and products they are also making them for themselves. That is why it is so easy for young people to take it. As stated earlier, the ever-increasing digitization of the present society only further stimulates the use of digital equipment and resources. This makes it virtually impossible for young people to be able to design their daily lives without the systematic and extensive use of these digital resources and equipment. As stated by the European Union: "While younger generations may find it difficult to imagine life without a smart phone or a personal computer, there were still two fifths (40\%) of older people (aged 65 74 years) in the EU-28 in 2017 who had never used a computer."

Figure 4 shows, in comparative terms, the non-use of the internet in the previous three months by age class, for 2017: 16-74 years; 5564 years; 65-74 years. It turns out that the 16-74 year olds are the ones that most accessed the internet, as opposed to the older citizens. When comparing the two bands of older citizens the differences can be considered very significant. These major differences are around $30 \%$ where Portugal is one such example. In another sense we find 
countries where this difference is much smaller (around 10\%) and which corresponds to countries in northern and central Europe. If we recall the fact that the aging process will accelerate with the doubling of $80+$ year olds, this difference with citizens up to 80 is expected to be even greater than the $30 \%$ already mentioned. Thus it is supposed to believe that the risks of a digital divide could be even greater. But instead, one can take into account a contrary opinion that is more optimistic and which is defended by the European Union in stating: "Older people are likely to make far greater use of ICTs in the future, given the continuing digitalization of society and an increasing number of tech savvy people (and others with some ICT skills) passing into older age."

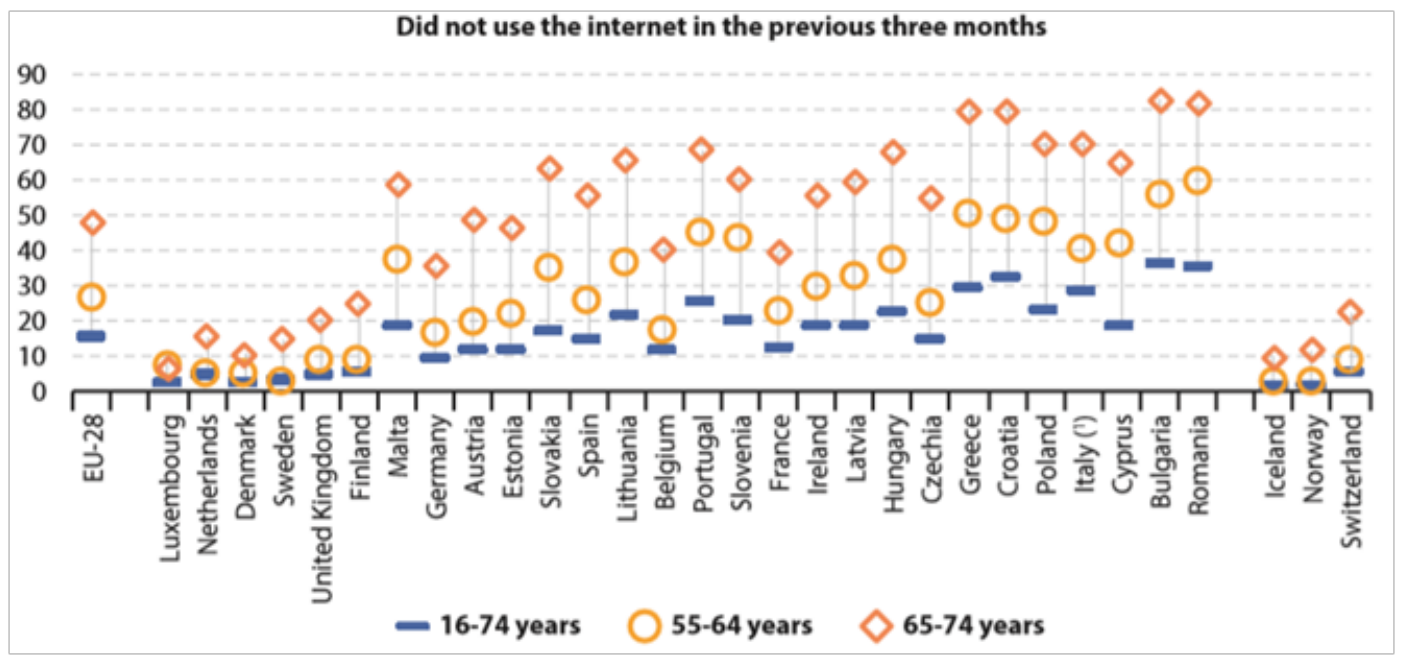

Figure 4 Digital skills of people, by age class (16-74 year; 55-64 years; 65-74 years).'

The European Union began to take action following the so-called Lisbon strategy which took place in 2005 and member states agreed to start developing initiatives and strategies for building a fully inclusive information society. It was in the understanding of the European Union that society was facing a change that would have to face and give adequate answers to the new challenges: "Recent technological progress has been huge and ICT are entering a phase of mass deployment which may fundamentally change the way in which we work, live and interact "(European Union, 2005, p. 4). In line with the i2010 initiative, it was supposed that structures were created so that information and communication technologies could benefit all citizen

$\mathrm{s}$, with better cost-effective public services and increased accessibility to improve the quality of life of citizens. To this end, priority was also given to meeting the needs of older people so that technologies could lead to healthier aging and also increase the levels of autonomy and independence of these citizens.

Following the i2010 initiative, a summit was held in Riga (June 2006) involving all 34 countries resulting in the well-known Ministerial Declaration - Riga Declaration which agreed to take steps towards a more inclusive and barrier-free information society. The year 2005 data on the use of digital technologies were very alarming as only $57 \%$ of EU citizens used the internet. Of these citizens only $10 \%$ aged $65+$ used the internet and only $24 \%$ of low educated citizens used the internet. Only younger citizens aged 1624 made the most use of the internet by presenting a value of $68 \%$. As we can see the picture was very bad and policy makers felt the need to provide a more global and concerted response to e-inclusion. The Riga Declaration (2006) approved 46 measures in the following areas: address the needs of older workers and elderly people; enhance e Accessibility and usability; promote cultural diversity in relation to inclusion; and, promote inclusive e Government.

The i2010 initiative has evolved into a new designation (European i2010 initiative on e-Inclusion - To be part of the information society) ${ }^{3}$ to make clearer the goal of creating an information society for all so that equality must be ensured for all citizens. In this sense, priority has been given to the need to promote digital literacy to reduce the gap between the EU population to avoid the risk of exclusion and therefore to compromise quality of life (Commission of the European Communities, 2007). ${ }^{3}$

In 2010, the Digital Agenda for Europe ${ }^{4}$ was introduced in order to respond to the low digital literacy of citizens because $30 \%$ had never used the internet despite the measures that had been taken since the year 2005. The biggest concerns were accessibility and usability especially for disabled citizens. Another priority has continued to be digital skills so that the use of digital technologies can be done safely. With particular regard to older people the Digital Agenda has proposed a measure called Ambient Assisted Living (AAL) that would allow telecare and online support for social services "to establish new ways to put ICT at the service of the most vulnerable members of the society (...) doubling the take-up of independent living arrangements for the elderly" (European Commission, 2010, p. 29). As you can see this is an incessant struggle but one that is progressing positively despite still feeling that much remains to be done. The positive note is that the EU-28 is aware of this issue and is continuing to take measures and initiatives that will continue to foster increased digital inclusion for all citizens.

In Portugal the first initiative took place in 1997 with the publication of the Green Book for the Information Society in Portugal which included the following areas: education, business, market and industry, social and legal implications, research and development. In 2008 a Technology Plan was launched with a greater focus on education and many e Government related initiatives were also implemented.

After a few years the ENILD - National Strategy for Inclusion and Digital Literacy (2015-2020) by the Foundation for Science and Technology is published in 2015. Given that in 2004, although $97 \%$ of $16-24$ year olds made use of the internet, $76 \%$ of the $55-74$ population still did not use the internet. For this reason, Enild, ${ }^{5}$ has prioritized the development of digital skills by: defining and applying a framework for digital skills; implementation of a nationwide network to mobilize 
a national infrastructure; compile and make available a wide range of training resources. In the field of digital skills, Enild, ${ }^{5}$ had as its main priority dimensions: information; the communication; content creation, security; and problem solving. To this end, the planned actions aimed to consolidate the 'ICT and Society Network' as a nationwide multi-stakeholder platform for digital inclusion and literacy, to list and provide up-to-date information in different directories (digital facilitators; free public hotspots with internet access, assistive technologies and training resources as well as digital inclusion and literacy actions and training), maximize the involvement of Safe Internet Center partners and create a gallery of patrons with the award (Patron of the Year).

The most recent initiative in Portugal was created in 2018 and is called Portugal INCoDe.2030-National e2030 Digital Skills Initiative. The main challenges of Incode, ${ }^{6}$ are at three levels: 1. Citizenship: Generalizing digital access, use and literacy for the full exercise of citizenship and promoting inclusion in an increasingly dematerialized society where much social interaction It occurs on the Internet and is increasingly mediated by electronic devices; 2. Employment: Stimulating employability, training and expertise in digital technologies and applications to meet growing market demand and to promote job skills and a higher value-added economy; 3. Knowledge: Ensure strong participation in international R\&D networks and knowledge production in digital areas. In turn, this national initiative is divided into five axes distributed by several ministries of the Portuguese government: Inclusion; Education; Qualification; Specialization; and Research. Among these five axes, the Inclusion axis stands out since it is the one that has the closest relationship with the older population that has been discussed: "To achieve this, it is necessary to design and implement inclusion initiatives and programs. flexible enough to respond to different needs and capable of overcoming a number of obstacles and limitations, notably of citizens who are already out of formal education and even vocational training, unemployed people, at-risk youth, migrants and minorities, seniors or with special needs" Incode. ${ }^{6}$ The main concern is to ensure that contexts of equity and social cohesion can be guaranteed, to promote balanced and sustainable development and to properly prepare the population for the future that will be eminently digital. Despite the different and consistent initiatives implemented over the last few years the struggle is not easy but there has been an improvement that progresses towards full digital inclusion.

Figure 5 shows the percentage values related to the population that has never used the internet with the EU averaging 14\%. Compared to some EU countries there is some discrepancy. Portugal is the one with the highest value with $26 \%$. In the opposite direction Finland has the lowest value with only $4 \%$.

Figure 6 presents the challenges for Portugal that are expected to be met through the implementation of the measures that integrate Portugal INCoDe.2030. In other words, Portugal intends to promote an evolution that began in 2002 with values that exceeded $60 \%$ so that in 2010 it reaches $20 \%$, in $202510 \%$ and in 2030 Only $5 \%$ of the population has not yet used the internet.

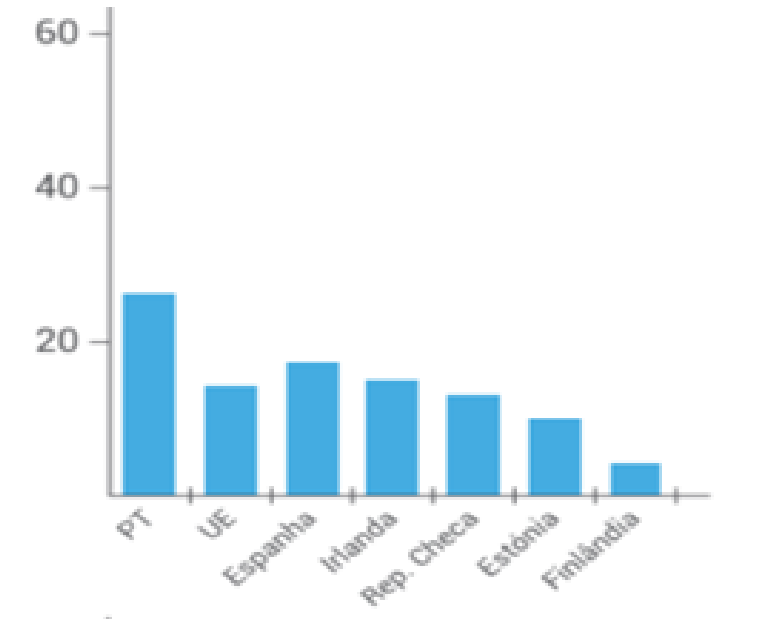

Figure $\mathbf{5} \%$ of individuals who have never used the internet-european comparison. ${ }^{6}$

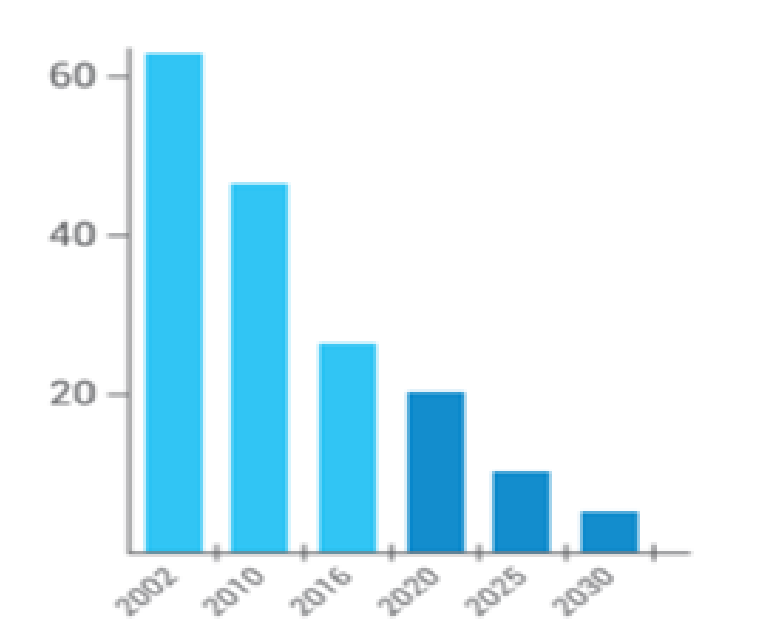

Figure 6 Expected evolution over the period 2020-2030 related to the percentage of the population not using the internet. ${ }^{6}$ 


\section{Strategies and proposals for digital inclusion of the elderly: theory of acceptance and use of technology, universal design, usability and accessibility}

Often when thinking about digital technologies, one tends to give importance to the purely technological aspect and for this reason neither gives much importance to the personal and social aspects that are inherent in their use and acceptance. For this reason, the so-called Human-Computer Interaction (HCI) is not given much importance. But this question, as Oshlyansky et al. ${ }^{7}$ may be decisive in the attitudes that individuals may take in order to accept or not accept and/or use a certain technology. In this context, Oye et al. ${ }^{8}$ cite Bagozzi, Davis and Warshaw in stating that technologies are complex and this fact makes people have doubts and even some fears about using them and also question the need to work hard so that they can learn to work with them. Possible reasons may be, according to Oye et al: "Attitudes towards usage and intentions to use may be ill-formed or lacking in conviction or else may occur only after preliminary strivings to learn to use the technology evolves."

Due to this complexity and difficulty in finding the most appropriate way to facilitate the adoption of new technologies, several models have been proposed: Theory of Reasoned Action (TRA), Technology Acceptance Model (TAM), Motivational Model (MM), Theory of Planned Behavior (TPB), Combined Theory of Planned
Behavior/Technology Acceptance Model (CTPB-TAM), Model of PC Utilization (MPCU), Innovation Diffusion Theory (IDT), and the Social Cognitive Theory (SCT). These models have been complementing each other and trying to remedy some weaknesses of each of them. There is a model that has been a kind of reference and was proposed by Davis ${ }^{9}$ which is called Technology Acceptance Model (TAM) which, in general terms, is based on: uses perceived usefulness (the degree to which a person believes that using a particular system would enhance his or her job performance) and perceived ease of use (the degree to which a person believes that using a particular system would be free of effort). However, after application in different areas it was felt that there were issues that could not be properly understood. And, taking into consideration the research done by Venkatesh et al. ${ }^{10}$ a reformulation they proposed include new variables associated with the social context and the affective and / or emotional issues that have been renamed. by: Unified Theory of Acceptance and Use of Technology - UTAUT. Figure 7 allows to make more evident the variables that justify the UTAUT proposal:

According to Moran $\mathrm{M}$ et al, ${ }^{11}$ it cannot be stated that this model can answer all the variables associated with the acceptance and use of technologies, but " the UTAUT model has been demonstrated to be up to $70 \%$ accurate at predicting user acceptance of information technology innovations. By generating a significantly higher percentage of technology innovation success the UTUAT is deemed a superior metric than the prior models.

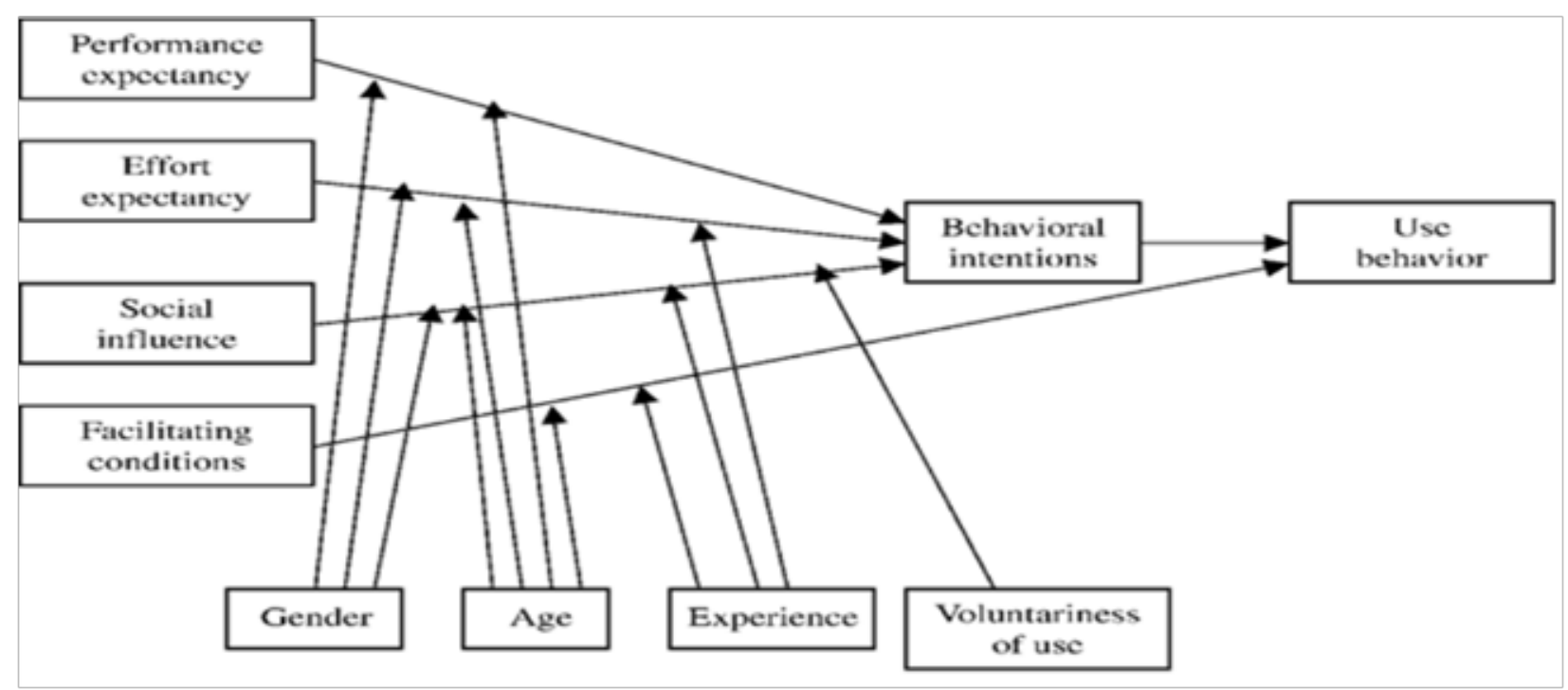

Figure 7 UTAUT-unified theory of acceptance and use of technology model. ${ }^{10}$

In order to continue to seek an appropriate response to the elderly, the concept of Universal Design may be a valence to consider. As stated by Aslaksen et al. ${ }^{12}$ disability is clearly related to age, $70 \%$ of all disabled are over 45 years and investigations show that permanent disability has an effect on the possibilities for education, work and social participation. For these reasons, these disabilities prevent older people from performing their duties like other citizens, and it is in this respect that the concept of universal design can be an asset in allowing everyone to access and use whatever equipment regardless of its disabilities. To this possibility Aslaksen et al. ${ }^{12}$ designate by 'The principle of equal status'. As stated by Story "13 "Universal Design can be defined as the design of products and environments that can be used and experienced by people of all ages and abilities, to the greatest extent possible, without adaptation." This means that universal design is designed to meet anyone's needs whatever their disability, gender, age, height and whatever context or environment ... in the sense of everyone, without exception, they may benefit from given equipment. In order for this to occur, the design must take into account its adaptability and flexibility. The seven principles governing Universal Design are as follows:

i. Principle 1: Equitable Use: the design is useful and marketable to people with diverse abilities.

ii. Principle 2: Flexibility in Use: the design accommodates a wide range of individual preferences and abilities.

iii. Principle 3: Simple and Intuitive Use: use of the design is easy to understand, regardless of the user's experience, knowledge, language skills, or current concentration level. 
iv. Principle 4: Perceptible Information: the design communicates necessary information effectively to the user, regardless of ambient conditions or the user's sensory abilities.

v. Principle 5: Tolerance for Error: the design minimizes hazards and the adverse consequences of accidental or unintended actions.

vi. Principle 6: Low Physical Effort: the design can be used efficiently and comfortably and with a minimum of fatigue.

vii. Principle 7: Size and Space for Approach and Use: appropriate size and space is provided for approach, reach, manipulation, and use regardless of the user's body size, posture, or mobility.

As can be seen from the reading of the seven principles, we find aspects related to accessibility and, to some extent, to transgenerational adaptation. Figure 8 shows schematically the relationship between these different dimensions:

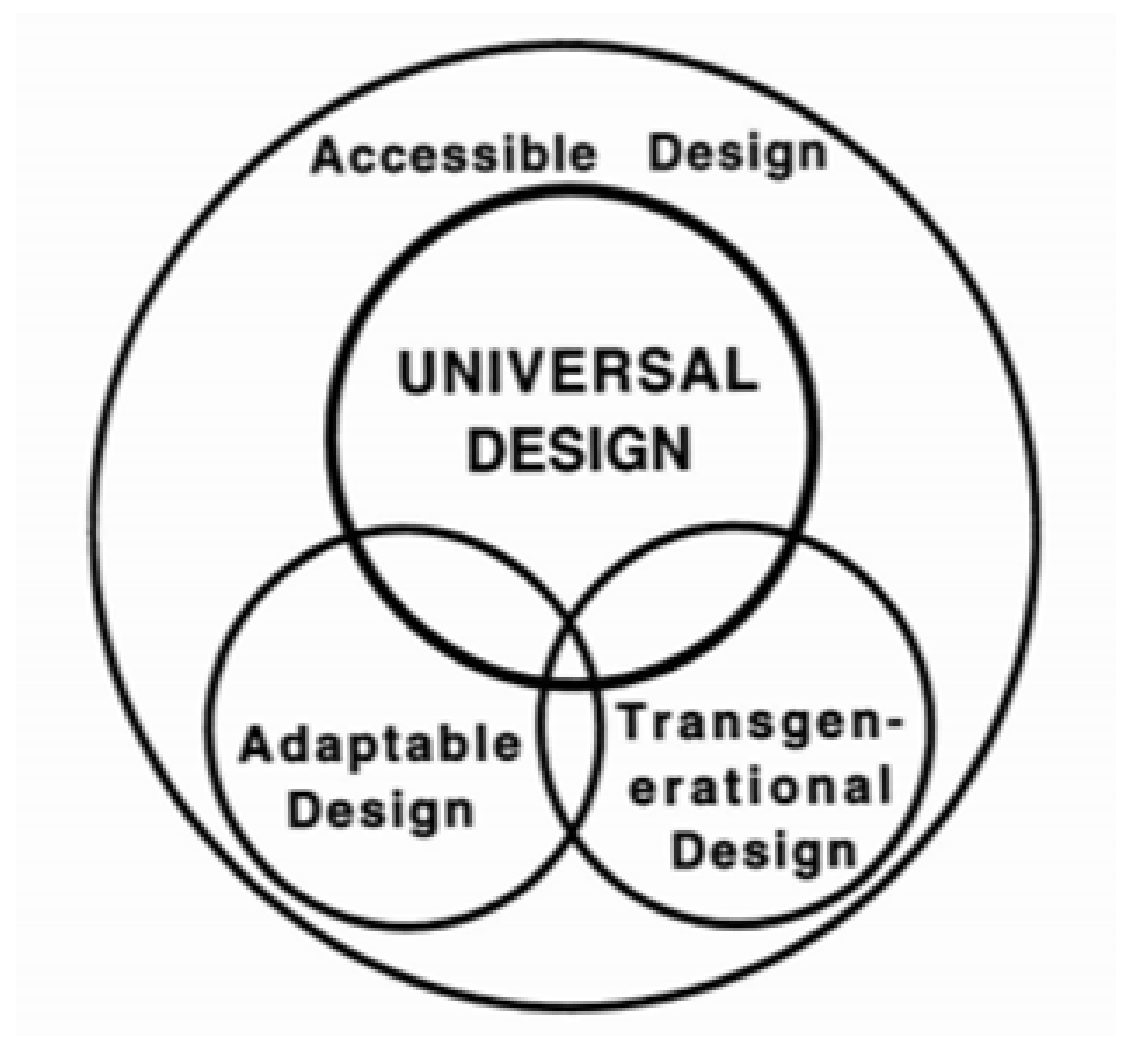

Figure 8 The relationship between accessible, adaptable, transgenerational, and universal design. ${ }^{13}$

Focusing on the transgenerational dimension Story ${ }^{13}$ cites Pirkl referring to this dimension, associating it with the need for universal design to take into account all the modifications and changes that individuals undergo during their aging process. According to Story: ${ }^{13}$ "Some universal design is transgenerational, but the approach is inclusive of more than just age-related disabilities. Universal design, then, is sometimes adaptable and sometimes transgenerational but always accessible." What is behind the concept of universal design is that it minimizes the effort of individuals to adapt to equipment so as to maximize their natural inclusion within their daily routine. We share the view of Aslaksen et al. ${ }^{12}$ in order to ensure the integration of the elderly in society in an intervening way and the universal design can be decisive: "The thinking related to universal design discusses the fact that large user groups are not able to use the products and the physical environment which we produce, and that it prevents them from participating in society."

Throughout this article we have been promoting a critical, albeit brief, presentation on the key variables associated with greater facilitation of older people to access and use digital resources. Following a reflection on universal design, usability and accessibility issues are closely related. In general terms usability problems are caused by the difficulty in matching users' capabilities and the capabilities required by the equipment in order to be able to be used. On the other hand, contexts and environments have to be taken into account because social variables may promote the need for other capacities. For this reason it is essential to know as much as possible about the capabilities and capabilities of each individual. In this sense, in the opinion of Wellie ${ }^{14}$ two dimensions associated with usability should be taken into account: (a) improving usability by evaluation with users and (b) improving usability already during design by applying all available relevant knowledge. There are several ISO standards and there has been greater consensus on ISO 9241-11 which has been the basis for reformulations and adaptations given the complexity related to the theoretical and practical concept of usability. ${ }^{14}$ In this sequence, proposals from Dix et al. ${ }^{16}$ have been relevant to clarify the areas and subareas where usability has to be focused. To better understand these different areas and their interrelationships, Figure 9 presents a scheme where this complexity is visible.

In this model Wellie, Veer and Eliëns emphasize the priority for the evaluation phase with current usage and evaluation during design process. The advantage is that you can follow and check almost immediately what needs to be improved, what needs to be changed or 
removed. But this process is also very complex and delicate because a given change can start a new design which will lead to a new cycle. As has been stated and demonstrated, the concept of usability is to make technology accessible and usable by disabled and non-disabled people. ${ }^{16}$ In the case of the elderly we can have individuals without disabilities even those with various disabilities. And, to make this reality even more complex, Petrie et al. ${ }^{17}$ state that research in this area has not been paying attention to the elderly, which will cause this population to face even more difficulties in accessing and using digital technologies. But this reality is even understandable because as Jokela et al..$^{18}$ refer "the identification of different users and the categorization of them into the appropriate user groups is not a trivial thing". For, as is well known, any product or equipment can have multiple users each having different capabilities and different goals, and at the same time each has different levels and concepts of effectiveness, efficiency and personal satisfaction. And if we are aware that the group of the elderly corresponds to the most heterogeneous social group the difficulties and the complexity of this problem is even greater. ${ }^{19-21}$

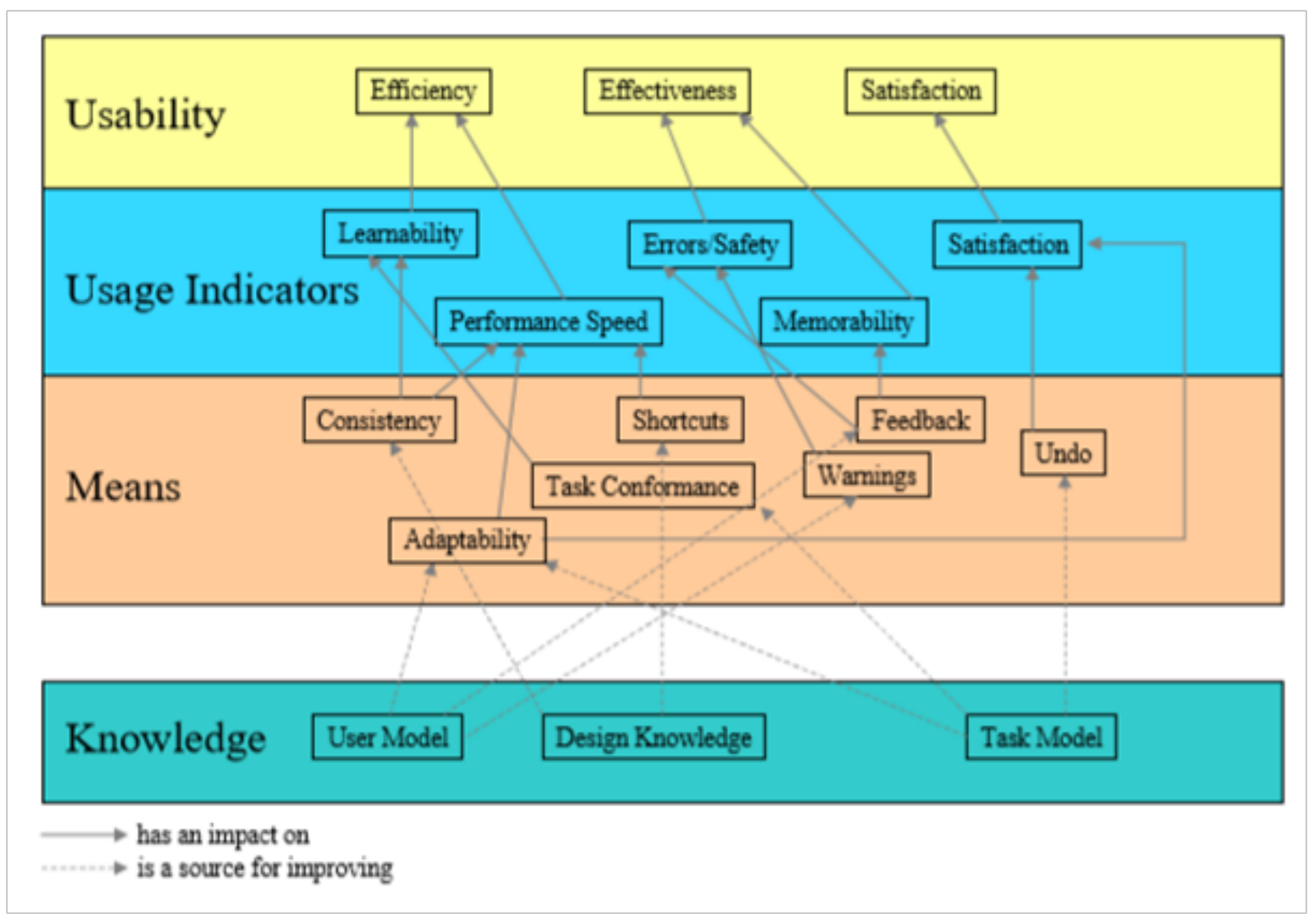

Figure 9 Layered model of usability. ${ }^{14}$

\section{Conclusion}

Throughout the article there was a concern to define a risk group in relation to digital exclusion: the elderly. A global characterization at EU-28 and Portugal level in relation to the aging process was presented, bridging the digital divide levels of older citizens. Subsequently, the efforts made in the EU-28 and Portugal related to the various initiatives leading to greater digital inclusion were presented in chronological order, always making a particular framework for the elderly. In a later section there was a presentation associated with theories, models and concepts that can and should be used in the design of technological resources and equipment in order to facilitate access and use by the elderly. In this regard, we highlight the Unified Theory of Acceptance and Use of Technology -UTAUT, the concept of Universal Design and the model associated with Usability.

Taking a reflexive and critical balance we get the feeling that there is still much to fight for. It is important that policy makers remain alert and concerned about the digital divide, but it is important that designers and industry focus more on the old user and not the young. In terms of business, the elderly will be the most populous age group and for this reason they will be the largest consumers in the future. One aspect that was not presented and discussed in this article has to do with the so-called user-centric design or approach. But this allusion was made that in the various stages of the design of a new equipment its end users should be involved, which in this case we want to be present in this process, at all stages the elderly.

But we have to think about the new digital technologies of the present (Internet of Things; Augmented Reality; Virtual Reality) and the near future with emphasis on Artificial Intelligence, Robotics, haptic devices and gadgets ... So we have to reinvent new strategies and new models that can include the elderly in a whole that will be eminently digital!

\section{Acknowledgements}

None. 


\section{Conflict of interests}

Authors declare that there is no conflict of interest

\section{References}

1. European union. Ageing Europe - Looking at the lives of older people in the EU-2019 edition. Luxembourg: Publications Office of the European Union; 2019:162.

2. European union. The 2018 Ageing report-economic \& budgetary projections for the EU 28 member states (2016-2070). Luxembourg: Publications Office of the European Union; 2019:406 .

3. Commission of the European communities. European i2010 initiative on e-Inclusion - To be part of the information society. Luxembourg: Publications Office of the European Union; 2007:11.

4. European Union. i2010 - A European information society for growth and employment. Luxembourg: Publications Office of the European Union; 2005:12.

5. ENILD. Estratégia nacional para a inclusão e literacias digitais (20152020). Lisboa: FCT; 2015:28

6. https://www.incode2030.gov.pt/

7. Oshlyansky L, Cairns P, Thimbleby H. Validating the unified theory of acceptance and use of technology (UTAUT) tool cross-culturally. British computer society volume 2 of the $21^{\text {st }}$ BCS HCI group conference HCI 2007; Lancaster, UK; 2007.

8. Oye ND, Iahad, NA, Rahim. The history of UTAUT model and its impact on ICT acceptance and usage by academicians. Educ Inf Techol. 2014;19:251-270.
9. Davis FD. Perceived usefulness, perceived ease of use, and user acceptance information technology. MIS Quarterly. 1989;13(3):319-339.

10. Venkatesh V, Morris MG, Davis GB, et al. User acceptance of information technology: toward a unified view. MIS Quarterly. 2003; 27:425-478.

11. Moran M, Hawkes M, Gayar O. Tablet personal computer integration in higher education: applying the unified theory of acceptance and use technology model to understand supporting factors. Journal of Educational Computing Research. 2010;42(1):79-101.

12. Aslaksen F, Bergh S, Bringa O, Universal design - planning and design for all. NC state university: The center for universal design; 1995:32.

13. Story MF. Maximizing usability: the principles of universal design. Asst Technology. 1998;10:4-12.

14. https://www.cs.vu.nl/ gerrit/gta/docs/Interact99.pdf

15. Nielsen J. Usability engineering. London: Academic Press; 1993:362.

16. Dix A, Abowd G, Beale R, et al. Human-computer interaction. Essex: Prentice Hall; 1998:52.

17. http://eprints.whiterose.ac.uk/109264/1/2015W4APetrieSavvaPower.pdf

18. h t t p : / / c i t e s e e r x. is t.p s u.e d u/vie w d o c/ download?doi=10.1.1.839.3339\&rep=rep1\&type $=$ pdf

19. European commission. A digital agenda for europe. Brussels: Publications Office of the European Union; 2007:41.

20. ISO/IEC. 9241-14 Ergonomic requirements for office work with visual display terminals. ISO/IEC; 1998.

21. https://ec.europa.eu/information_society/activities/ict_psp/documents/ declaration riga.pdf 